\title{
Efficacy of acetaminophen in skin B16-F0 melanoma tumor-bearing $\mathrm{C} 57 \mathrm{BL} / 6$ mice
}

\author{
NIKHIL M. VAD ${ }^{1}$, SHASHI K. KUDUGUNTI ${ }^{1}$, DANIEL GRABER ${ }^{1}$, \\ NATHAN BAILEY ${ }^{1}$, KALKUNTE SRIVENUGOPAL ${ }^{1}$ and MAJID Y. MORIDANI ${ }^{1,2}$ \\ ${ }^{1}$ Department of Pharmaceutical Sciences, School of Pharmacy, ${ }^{2}$ Department of Pediatrics, \\ School of Medicine, Texas Tech University Health Sciences Center, Amarillo, TX 79106, USA
}

Received January 29, 2009; Accepted April 3, 2009

DOI: 10.3892/ijo_00000329

\begin{abstract}
Previously, we reported that acetaminophen (APAP) showed selective toxicity towards melanoma cell lines. In the current study, we investigated further the role of tyrosinase in APAP toxicity in SK-MEL-28 melanoma cells in the presence of a short hairpin RNA (shRNA) plasmid, silencing tyrosinase gene. Results from tyrosinase shRNA experiments showed that APAP led to negligible toxicity in shRNA plasmidtreated cells. It was also found that APAP selectively caused escalation in reactive oxygen species (ROS) formation and intracellular GSH (ICG) depletion in melanocytic human SKMEL-28 and murine B16-F0 melanoma cells that express functional tyrosinase whereas it lacked significant effects on ROS formation and ICG in amelanotic C32 melanoma cells that do not express functional tyrosinase. These findings suggest that tyrosinase plays a major role in APAP selective induced toxicity in melanocytic melanoma cell lines. Furthermore, the in vivo efficacy and toxicity of APAP in the skin melanoma tumor model in mice was investigated. Mice receiving APAP at 60, 80, 100 and $300 \mathrm{mg} / \mathrm{kg} /$ day, day 7 through 13 post melanoma cell inoculation demonstrated
\end{abstract}

Correspondence to: Dr Majid Moridani, Department of Pharmaceutical Sciences, School of Pharmacy, Texas Tech University Health Sciences Center, 1300 S Coulter Drive, Amarillo, TX 79106 , USA

E-mail: majid.moridani@ttuhsc.edu

Abbreviations: acetaminophen, APAP; modified Eagle's medium $\alpha$, MEM; fetal bovine serum, FBS; phosphate-buffered saline, PBS; Dulbecco's modified Eagle's medium, DMEM; Minimum essential Medium, MEM; reactive oxygen species, ROS; [3-(4, 5-dimethylthiazolyl-2)-2, 5-diphenyl tetrazolium bromide], MTT; diethylenetriaminepentaacetic acid, DETAPAC; 5,5'-dithiobis-2-nitrobenzoic acid, DTNB; sulphosalicylic acid, SSA; thiobarbituric acid reactive substances, TBARS; alanine aminotransferase, ALT; short hairpin RNA, shRNA; phenylmethylsulphonyl fluoride, PMSF

Key words: acetaminophen, melanoma, tyrosinase, acetaminophen, SK-MEL-28, C32, C57BL/6 mice, MeWo, SK-MEL-24, SK-MEL-5, phenacetin, short hairpin RNA tumor size growth inhibition by $7 \pm 14,30 \pm 17,45 \pm 11$ and $57 \pm 3 \%$, respectively. Mice receiving APAP day 1 through 13 post melanoma cell inoculation showed tumor size growth inhibition by $11 \pm 7,33 \pm 9,36 \pm 20$ and $44 \pm 28 \%$, respectively.

\section{Introduction}

Malignant melanoma is the most dangerous form of skin cancer. According to World Health Organization statistics, the incidence of melanoma cases worldwide is increasing faster than any other cancer (1). Current estimates suggest a doubling of melanoma incidence every $10-20$ years $(2,3)$. Novel chemotherapeutic agents for the treatment of patients with disseminated malignant melanoma are urgently needed.

Tyrosinase has previously been used as a molecular target in melanoma-directed prodrug therapy (4-7). Using this approach, 4-hydroxyanisole (4-HA) was investigated in melanoma clinical trials but was withdrawn due to liver and kidney toxicity (8). We have previously reported that 4-HA was also bioactivated by liver P450 enzymes to reactive oquinone, which contributed to its liver toxicity (6). Because drug metabolism, pharmacokinetics and drug induced liver and kidney toxicity continue to be major limiting factors in today's drug discovery endeavors, our efforts were directed towards optimizing lead phenolic-based prodrugs with selective efficacy towards melanoma but with minimal liver and kidney toxicity. Recently, we investigated the in vitro toxicity of acetaminophen (APAP) in melanoma and non-melanoma cell lines (9). The study suggested that APAP is selectively toxic towards melanoma cells. In the current study, in order to further elucidate the role of tyrosinase, we investigated APAP toxicity by silencing tyrosinase using shRNA constructs in cell culture experiments and in amelanotic melanoma cells which do not express functional tyrosinase. In addition, in vivo efficacy and toxicity of APAP were also investigated in a skin tumor model of B16-F0 melanoma in C57BL/6 mice.

\section{Materials and methods}

Materials. All materials, solvents and reagents used in this study were analytical grade with the highest degree of purity and were purchased either from Sigma-Aldrich, St. Louis, MO or Fisher-Scientific, Pittsburgh, PA. Picric acid (Cat. No. 5860-16) was obtained from Ricca Chemical, Arlington, TX. 
Mushroom tyrosinase was used in this study because purified human tyrosinase is not available commercially. DMSO was used to solublize APAP and phenacetin. Phosphate buffer (0.1 M, pH 7.4, containing DETAPAC $1 \mathrm{mM}$ ) was used to solublize ascorbic acid (AA), NADH and GSH.

Modified Eagle's Medium a (MEM) (1x) (Cat. no. 32571036), fetal bovine serum (FBS) (Cat. No. 10082-139), penicillin-streptomycin $(10,000 \mathrm{U} / \mathrm{ml})$, Cat. No. (15140-122) and trypsin-EDTA solution $1 \mathrm{x}(0.25 \% \mathrm{w} / \mathrm{v}-0.53 \mathrm{mM}$ EDTA $)$ (Cat. No. 30-2101) were purchased from American Type Culture Collection (ATCC ${ }^{\circledR}$ ), Manassas, VA. RPMI medium 1640 (1x) (Cat. no. 11875-119) was obtained from Invitrogen Corporation, Grand Island, NY. The human SKMEL-28 melanoma cell line was obtained from (ATCC No. HTB-72). The Saos-2 osteosarcoma, SW-620 colorectal adenocarcinoma and PC-3 prostate adenocarcinoma cell lines were a gift from Dr Jon Weidanz, Department of Pharmaceutical Sciences, Texas Tech University Health Sciences Center, Amarillo, TX. The SK-MEL-5 (ATCC No. HTB-70), SK-MEL-24 (ATCC No. HTB-71), C32 (ATCC No. CRL1585), MeWo (ATCC No. HTB-65), B16-F0 (ATCC No. CRL-6322), B16-F10 (ATCC No. CRL-6475) melanoma and BJ fibroblast cell lines (ATCC No. CRL-2522) were obtained from ATCC.

The SureSilencing shRNA plasmid (Cat. No. KH01771N for the neomycin resistance) for human tyrosinase was obtained from SuperArray Bioscience Corporation, Frederick, MD. The anti-tyrosinase monoclonal antibody $(232 \mu \mathrm{g} / \mu \mathrm{l}$; Cat. No. 05-647) was obtained from Upstate Innovative Cell Signalling Solutions, Lake Placid, NY.

Cell culture. The cell culture experiments were performed, as described previously (9-11). Human SK-MEL-28 melanoma cells contained in frozen vials were washed twice with MEM $\alpha$ media before culturing in $10 \mathrm{ml}$ media supplemented with (10\%) fetal bovine serum (FBS) and streptomycin/penicillin $(100 \mathrm{U} / \mathrm{ml})$ in a T-25 flask (12). The cultures were kept at $37^{\circ} \mathrm{C}$ under a $5 \% \mathrm{CO}_{2}$ atmosphere in a TS Auto flow $\mathrm{CO}_{2}$ Water-Jacketed Incubator (Forma Scientific, Marietta, $\mathrm{OH}$, USA). Upon attainment of $\sim 90 \%$ confluency, media were removed and trypsin-EDTA solution $(2-5 \mathrm{ml})$ was used to detach cells. The detached cells were rinsed with $\sim 10 \mathrm{ml}$ of pre-warmed sterile phosphate-buffered saline (PBS) at $37^{\circ} \mathrm{C}$ to dilute trypsin. The mixture was transferred into a $50 \mathrm{ml}$ tube. The flask was additionally rinsed with sterile PBS and the contents were added to the rest of the cells collected. The cells were spun down at $800 \mathrm{rpm}$ (Beckman GPR Centrifuge, Fullerton, CA) for 3-5 min. Pelletted cells were re-suspended in MEM $\alpha$ media supplemented by (10\%) FBS and streptomycin/penicillin $(100 \mathrm{U} / \mathrm{ml})$ followed by splitting the mixture into one T-75 flask containing $33 \mathrm{ml}$ media (25\% of the media were supplemented from the previous culture step as conditioning media). After reaching a confluency of $90 \%$, the cells obtained from each flask were further split into three T-75 flasks in a similar manner (10).

A similar approach was used to grow skin fibroblast BJ cells, prostate PC-3, osteosarcoma Saos-2, colorectal adenocarcinoma SW-620, amelanotic SK-MEL-24 and C32 melanoma cells and melanocytic SK-MEL-5, B16-F0, B16-F10 and MeWo melanoma cells. MEM $\alpha$ media was used to culture human SK-MEL-28 cells, SK-MEL-5, MeWo, SK-MEL-24, C32 and BJ cells. B16-F0 cells and B16-F10 cells were cultured using DMEM media (Gibco Cat. No. 11965). The Saos-2 cells were cultured using McCoy's 5A Medium (ATCC Number: 30-2007) while the SW-620 cells were cultured in Leibovitz's L-15 medium (ATCC Number: 302008). The PC-3 cells were cultured using RPMI media (Gibco Cat No. 11875-093).

Cell viability assay. Cell viability was determined, as described previously (9-11). To evaluate cytotoxicity, cells were obtained from exponentially growing $90-95 \%$ confluent cultures. The BJ, PC-3, Saos-2, SW-620, B16-F0, B16-F10, SK-MEL-28, SK-MEL-24, C32 and MeWo cells were seeded at 40,000 cells/well in 24-well plates while SK-MEL-5 cells were seeded at 4,000 cells/well.

For instance, SK-MEL-28 cells obtained from each flask were suspended in $4 \mathrm{ml}$ of MEM $\alpha$ media supplemented by (10\%) FBS and streptomycin/penicillin (100 U/ml). The cells were then counted using the trypan blue exclusion method for determining the viability (13). SK-MEL-28 melanoma cells were seeded at 40,000 cells/well in 24-well plates. The cells were grown in $400 \mu \mathrm{l}$ fresh MEM $\alpha$ media supplemented by $10 \%$ FBS and streptomycin/penicillin $(100 \mathrm{U} / \mathrm{ml})$. The cells were allowed $24 \mathrm{~h}$ for cell adhesion and environmental adaptation. Subsequently, the cells were treated with an additional $600 \mu \mathrm{l}$ of respective media containing various concentrations of APAP or phenacetin for 24 and $48 \mathrm{~h}$. The media were removed and the wells were washed twice using respective media before adding $160 \mu \mathrm{l}$ of $2 \mathrm{mg} / \mathrm{ml}$ yellow tetrazolium dye [3-(4, 5-dimethylthiazolyl-2)-2, 5-diphenyl tetrazolium bromide] (MTT) (12). The plates were returned to the incubator for a period of $4 \mathrm{~h}$. The residual MTT solution was removed from the wells and then $800 \mu 1$ of DMSO was added to each well. The plates were stored at room temperature in a dark place for an additional $2 \mathrm{~h}$ before reading the absorbance at $570 \mathrm{~nm}$ using SpectraFluor Plus plate reader (Tecan Inc, Santa Margarita, CA). All experiments were performed in triplicate.

$I C_{50}(48 \mathrm{~h})$ calculation. The required concentration $\left(\mathrm{IC}_{50}\right.$ in $\mu \mathrm{M})$ of APAP or phenacetin that can lead to $50 \%$ decrease in SK-MEL-28 melanoma cell viability $48 \mathrm{~h}$ after incubation was calculated from the logarithmic regression equation derived from graphing the viability of the cells at $48 \mathrm{~h}$ vs. the concentration of APAP or phenacetin.

Intracellular GSH measurement. Intracellular GSH was determined in human melanocytic SK-MEL-28, murine melanocytic B16-F0 and human amelanotic C32 melanoma cells based on a modified recycling method $(9,14)$. In this reaction, GSH reacts with DTNB to form the disulfide GSTNB and the yellow colored compound 5-thio-nitrobenzoic acid (TNB) was measured $(9,14)$.

Briefly, human melanocytic SK-MEL-28, murine melanocytic B16-F0 and amelanotic C32 melanoma cells obtained from exponentially growing 90-95\% confluent cultures and seeded at 1 million cells $/ \mathrm{ml}$ in MEM $\alpha$ media supplemented with $(10 \%) \mathrm{FBS}$ and streptomycin/penicillin $(100 \mathrm{U} / \mathrm{ml})$ in 24-well plates. The cells were incubated at $37^{\circ} \mathrm{C}$ for $3 \mathrm{~h}$ to 
allow for cell adhesion and environmental adaptation. Subsequently, the cells were treated with an additional $1 \mathrm{ml}$ MEM $\alpha$ media containing various concentrations of APAP $(100 \mu \mathrm{M}-1 \mathrm{mM})$ for 1,2 and $3 \mathrm{~h}$ respectively. For each time point, the media were removed, $100 \mu 1$ trypsin-EDTA solution was added to dislodge the cells, followed by addition of $100 \mu 1$ $3 \%$ sulphosalicylic acid (SSA) to lyse the cells. The cells were monitored under the microscope in order to ensure all cells were detached and in suspension. The cells were then centrifuged at $14,000 \mathrm{rpm}\left(4^{\circ} \mathrm{C}\right)$ for $10 \mathrm{~min}$. The supernatant was diluted 10-fold with phosphate buffer $(100 \mathrm{mM}$ containing EDTA $1 \mathrm{mM}$ ) pH 7.4. An aliquot of $50 \mu 1$ was added to respective wells in a 96-well plate. Master mix (100 $\mu \mathrm{l}$ ) (NADPH $0.3 \mathrm{mM}$, DTNB $0.225 \mathrm{mM}$, GSSG reductase $1.6 \mathrm{U} / \mathrm{ml}$ in phosphate buffer $100 \mathrm{mM}$ containing EDTA $1 \mathrm{mM}$, $\mathrm{pH}$ 7.4) was added to each well. Immediately upon addition of the master mix, color development was recorded at $405 \mathrm{~nm}$ at 9 time intervals of $30 \mathrm{sec}$ for 4 min using a Wallac 1420 microplate reader (Perkin Elmer Wallac, Turku, Finland) equipped with kinetic analysis software $(9,15)$.

Reactive oxygen species formation measurement. ROS formation was determined in human melanocytic SK-MEL-28, murine melanocytic B16-F0 and human amelanotic C32 melanoma cells, as described previously $(9,14)$. Melanocytic SK-MEL-28, melanocytic B16-F0, and amelanotic C32 cells were seeded at 50,000 cells per well in 96-well black microplates (Cat. No. 3603, Corning Incorporated, Corning $\mathrm{NY}$ ). The cells were incubated at $37^{\circ} \mathrm{C}$ for $2 \mathrm{~h}$ to allow for cell adhesion and environmental adaptation. The media was removed followed by addition of $100 \mu \mathrm{l}$ of 2',7'-dichlorofluorescein diacetate (16). Various concentrations of APAP (50-500 $\mu \mathrm{M})$ were added to the wells. Immediately upon addition, the plates were read at $\lambda_{\mathrm{em}}=535 \mathrm{~nm}$ using $\lambda_{\mathrm{ex}}=485$ over a period of 5-40 min by a SpectraFluor Plus plate reader (Tecan Inc).

Tyrosinase shRNA transfection. A panel of four short hairpin RNAs specifically directed against human tyrosinase were purchased from the Super Array Biosciences (Frederick, MD; Cat. No. KH01771N). This system consists of RNAi sequences cloned in plasmids under the U1 promoter, meant to express 22-mer ds-RNA sequences after transient or stable transfections. In initial experiments, the plasmids were amplified in E. coli and the DNAs purified by standard procedures (17). The RNAi insert sequences found in these plasmids were GTAGCCGATTGGAGGAGTACA, and CCAGAAGCTGACAGGAGATGA, and GACGACTCTTG GTGAGAAGAA, and TGAGCTTGCTGTGTCGTCACA and the non-specific scrambled sequence ggaatctcattcgatgc atac was used as a control. The tyrosinase-proficient SKMEL-28 cells $\left(2 \times 10^{6}\right)$ were transfected with the $1 \mu \mathrm{g}$ plasmid DNAs (of all shRNA clones) for $48 \mathrm{~h}$ using the FuGENE6 reagent (Roche Diagnostics Corporation, Indianapolis, IN). The cells were trypsinized, pelleted and washed twice with cold PBS. They were suspended in $50 \mathrm{mM}$ Tris/ $\mathrm{HCl}$ buffer (pH 8.0) containing 1\% glycerol, $1 \mathrm{mM}$ EDTA, $0.5 \mathrm{mM}$ phenylmethylsulphonyl fluoride (PMSF) and $2 \mathrm{mM}$ bezamidine and sonicated (Fisher sonic dismembrator, Model 100, Waltham, MA) and centrifuged (Eppendorf centrifuge,
Westbury, NY) to prepare cell-free extracts. Equal amount of proteins $(50 \mu \mathrm{g})$ in different treatments were electrophoresed on $12 \%$ SDS-polyacrylamide gels followed by transfer to Immobilon membranes (Immobilon-FL transfer membranes, Cat. No. IPFL00010, pore size $0.45 \mu \mathrm{m}$, Millipore, Bedford, CA). The blots were stained with $0.2 \%$ Ponceau-S to ensure equal protein loading. The membranes were then blocked with $3 \%$ non-fat dry milk in Tris-buffered saline $(\mathrm{pH} 8.0)$ containing $0.1 \%$ Tween-20 for $2 \mathrm{~h}$. Tyrosinase protein levels were detected by Western blotting with a specific anti-tyrosinase monoclonal antibody $(2 \mu \mathrm{g} / \mathrm{ml})$ (Upstate Innovative Cell Signaling Solutions). Antigen-antibody complexes were visualized by enhanced chemiluminescence. Band intensities were quantitated using the VersaDoc Imaging system and software (Bio-Rad, Richmond, CA).

shRNA3, which was most efficient in curtailing tyrosinase expression (Fig. 3A) was chosen for drug sensitivity experiments. Briefly, SK-MEL-28 cells were seeded at 160,000 cells/well in 6 -well plates. $24 \mathrm{~h}$ after seeding, the cells were transfected with the shRNA clone as described in the previous section. $24 \mathrm{~h}$ later, the untreated controls and the transfected cells along with the non-specific shRNA (negative control) transfected cells were treated with APAP $(100 \mu \mathrm{M})$ and incubated further for $48 \mathrm{~h}$. Cell viability was assayed by MTT assay (9) by the procedure detailed above. Results from three independent experiments in triplicate were averaged and presented.

Tyrosinase-mediated GSH depletion assay. A previously described method (9) was used to measure the extent of GSH depletion as a result of the enzymatic oxidation of APAP or phenacetin by tyrosinase $/ \mathrm{O}_{2}$. Briefly, tyrosinase $(10 \mu \mathrm{l}$; $2500 \mathrm{U} / \mathrm{ml})$ was added to a mixture of APAP $(100 \mu \mathrm{M})$ or phenacetin $(100 \mu \mathrm{M})$ and $\mathrm{GSH}(200 \mu \mathrm{M})$ in a final volume of $1 \mathrm{ml}$ phosphate buffer (0.1 M, pH 7.4, containing DETAPAC $1 \mathrm{mM})$. The mixture was incubated at $37^{\circ} \mathrm{C}$ in a water bath and $250 \mu \mathrm{l}$ aliquots were drawn at $30 \mathrm{~min}, 1$ and $2 \mathrm{~h}$, respectively. The aliquots were added to trichloroacetic acid $(25 \mu 1 ; 30 \%$ $\mathrm{w} / \mathrm{v})$, vortexed and left at room temperature for $5 \mathrm{~min}$. A $100 \mu \mathrm{l}$ aliquot of the supernatant was then added to a mixture of Ellman's reagent (DTNB) (18) $(25 \mu \mathrm{l} ; 2 \mathrm{mg} / \mathrm{ml})$ and Tris/HCl buffer $(875 \mu 1 ; 0.1 \mathrm{M}, \mathrm{pH} 8.9)$ and then vortexed. The absorbance of the solution was observed at $412 \mathrm{~nm}$ $(6,10,18,19)$. GSH depletion was used as the indication of the enzymatic oxidation of APAP or phenacetin by tyrosinase/ $\mathrm{O}_{2}$.

Rate of AA and NADH oxidation mediated by APAP metabolism by tyrosinase $/ \mathrm{O}_{2}$. A previously described method (9) was used to measure the rate of ascorbic acid (AA) and NADH oxidation mediated by APAP or phenacetin metabolism by tyrosinase $/ \mathrm{O}_{2}$. Tyrosinase $(5 \mathrm{U} / \mathrm{ml})$ was added to a mixture of APAP $(100 \mu \mathrm{M})$ or phenacetin $(100 \mu \mathrm{M})$ in the presence of AA $(50 \mu \mathrm{M})$ in phosphate buffer $(0.1 \mathrm{M}, \mathrm{pH} 7.4$, DETAPAC $1 \mathrm{mM})$. Similarly, to measure the rate of $\mathrm{NADH}$ oxidation, a concentration of APAP $(100 \mu \mathrm{M})$ or phenacetin $(100 \mu \mathrm{M})$ and tyrosinase $(5 \mathrm{U} / \mathrm{ml})$ was used with $\mathrm{NADH}$ $(200 \mu \mathrm{M})$. The depletion of AA and NADH were monitored at 266 and $340 \mathrm{~nm}$, respectively. The rate was calculated using the following formula: Rate of AA oxidation $=[$ change 
in AA absorbance/initial AA absorbance] x [AA $(\mu \mathrm{M}) / \mathrm{APAP}$ $(\mu \mathrm{M})] \times[1 /$ tyrosinase $(\mathrm{U} / \mathrm{ml})] \times[1 /$ time $(\min )]$. A similar formula was used to calculate the rate of NADH oxidation.

Animal housing and protocol. Male C57BL/6 mice (6-8 weeks old) were obtained from Charles River Laboratories, Wilmington, MA, fed ad libitum, were allowed to acclimatize for 1 week on clay chip bedding in a room with a $12 \mathrm{~h}$ light photo cycle, an environmental temperature of $21-23^{\circ} \mathrm{C}$ and $50-60 \%$ relative humidity. The animal protocols used in current investigation were reviewed and approved by Institutional Animal Care and Use Committee at Texas Tech University Health Sciences Center, Amarillo, TX.

Tumor cell inoculation and administration of drug. Male C57BL/6 mice (6-8 weeks old) were obtained from Charles River Laboratories, Wilmington, MS. Mice were inoculated subcutaneously on the shaved lateral right flank with $1 \times 10^{6}$ B16-F0 murine melanoma cells in $100 \mu 1$ PBS, pH 7.4 using a 25-guage needle (Becton-Dickinson, Cat. No. 305122, Franklin Lanes, NJ). Animals were randomized and assigned to different treatment groups for day 1-13 and day 7-13 therapy with different doses of APAP $(60-300 \mathrm{mg} / \mathrm{kg} /$ day in $120 \mu \mathrm{l}$ saline), respectively.

APAP in vivo efficacy study. Treatment of B16-F0 tumor bearing mice was initiated one day post melanoma cell inoculation. The treatment regimen consisted of a daily intraperitoneal injection of APAP injected at doses of 60, 80, 100 and $300 \mathrm{mg} / \mathrm{kg}$ in $120 \mu \mathrm{l}$ saline for the relevant treatment groups $(\mathrm{n} \geq 12)$. Untreated tumor bearing mice received $120 \mu 1$ saline alone. The animals were weighed on a daily basis. All animals were sacrificed $2 \mathrm{~h}$ post drug injection on day 13 after melanoma cell inoculation; subcutaneous tumors were excised and weighed. ALT plasma levels, the extent of lipid peroxidation and the free thiol content in the liver and kidney of C57BL/6 mice were measured as the indication of in vivo toxicity. Treatment initiated on day 7 post tumor cell inoculation was performed in a similar manner.

Plasma ALT levels. On day 13 after tumor cell inoculation, animals were anesthetized using $\sim 2-3 \%$ isoflorane $2 \mathrm{~h}$ post drug injection. Blood samples were drawn via heart tap into tubes with heparin (Baxter Healthcare Corporation; 10,000 USP U/ml; NDC No. 0641-0410-25; 1 part heparin and 9 parts blood). Blood plasma was separated from whole blood by centrifugation at 3,000 rpm (E.I. Dupont de Nemours \& Co., Newtown, CT; Cat. No. RC-5C) for 5 min at $4^{\circ} \mathrm{C}$. Plasma alanine aminotransferase (ALT) levels were determined using Biotron Assay kit (Cat. No. 68-D, Hemet, CA).

Estimation of lipid peroxidation in liver and kidney of mice. The malondialdehyde (MDA; as the measure of lipid peroxidation) content of the tissue homogenates were measured spectrophotometrically in the form of TBARS (Thiobarbituric acid-reactive substances) as described by Wills et al $(20,21)$. Briefly, 150-200 mg of tissue was mixed with 10 -fold distilled water and homogenized using a hand held homogenizer. Tissue $(0.5 \mathrm{ml})$ homogenate was mixed with an equal volume of Tris/ $\mathrm{HCl}$ buffer $(\mathrm{pH} 7.4)$ and was incubated at $37^{\circ} \mathrm{C}$ in a water bath for $2 \mathrm{~h}$. The blank sample contained a mixture of $0.5 \mathrm{ml}$ distilled water and $0.5 \mathrm{ml}$ Tris/HCl buffer ( $\mathrm{pH} 7.4)$. The reaction mixture was brought to $2 \mathrm{ml}$ with $1 \mathrm{ml}$ of $10 \%$ ice-cold trichloroacetic acid. After centrifugation $(5,000 \mathrm{x} \mathrm{g}, 10 \mathrm{~min}), 1 \mathrm{ml}$ of $0.67 \%$ thiobarbituric acid (Sigma-Aldrich; Cat. No. T5500) was added to $1 \mathrm{ml}$ of the supernatant. The tubes were then kept in a boiling water bath for $10 \mathrm{~min}$ and after cooling under tap water, $1 \mathrm{ml}$ of distilled water was added. Absorbance was measured at $540 \mathrm{~nm}$.

Estimation of free thiol content in liver and kidney of mice. Total sulfhydryl groups were determined by a modified method of Sedlak and Lindsay (22). Liver and kidney tissue were removed from mice. Tissue $(150-200 \mathrm{mg}$ ) was mixed with 10 -fold of $(1 \% \mathrm{w} / \mathrm{v})$ picric acid and homogenized using a hand held homogenizer. Aliquots $(600 \mu 1)$ of tissue homogenates were then mixed with $60 \mu 1$ of $(30 \%)$ trichloroacetic acid. The samples were then centrifuged at 7,500 rpm (Brinkmann Instruments Inc., Cat. No. 5417 C, Westbury, NY) for $10 \mathrm{~min}$. A $100 \mu 1$ aliquot of the supernatant was then added to a mixture of Ellman's reagent (DTNB) (100 $\mu \mathrm{l} ; 6 \mathrm{mM})$ and phosphate buffer $(800 \mu \mathrm{l} ; 0.1 \mathrm{M}$, pH 7.4, $1 \mathrm{mM}$ DETAPAC). The absorbance of the solution was observed at $412 \mathrm{~nm}$. Each sample was blanked with $100 \mu \mathrm{l}$ Ellman's reagent (DTNB) $(6 \mathrm{mM})$ and $900 \mu 1$ phosphate buffer (0.1 M, pH 7.4, 1 mM DETAPAC).

Statistical analysis. Statistical analyses of the data was performed using the post t-test after ANOVA and was considered to be significant at $\mathrm{P}<0.05$.

Partition coefficient. Partition coefficient values were estimated using the LogP program available at www acdlabs.com.

\section{Results}

Cell viability assay. The $\mathrm{IC}_{50}(48 \mathrm{~h})$ concentration was determined by MTT assay $(10,12)$ as a measure of melanoma cell viability. The $\mathrm{IC}_{50}(\mu \mathrm{M})$ is the required concentration of APAP or phenacetin that can lead to $50 \%$ decrease in SK-MEL-28 melanoma cell viability at $48 \mathrm{~h}$ after incubation with the drug. The regression analysis of the toxicity of these two compounds at various concentrations showed cytotoxicity to be dose- and time-dependent (data not shown). The $\mathrm{IC}_{50}$ of APAP and phenacetin [ $N$-(4-Ethoxyphenyl)acetamide] in SK-MEL-28 cells was determined to be 100 and $420 \mu \mathrm{M}$, respectively.

When tested at $100 \mu \mathrm{M}$ concentration, APAP showed considerable toxicity in SK-MEL-28, SK-MEL-5, MeWo cells (melanocytic human melanoma cell lines) and B16-F0 and B16-F10 cells (melanocytic murine melanoma cell lines) resulting in $50 \pm 3,40 \pm 3,45 \pm 7,34 \pm 8$ and $35 \pm 5 \%$ antiproliferative effects, respectively (Fig. 1). These results also indicate that human melanoma cell lines were more susceptible to APAP than murine B16-F0 and B16-F10 melanoma cells. When tested in amelanotic SK-MEL-24 and C32 cells that do not express functional tyrosinase $(23,24)$, APAP at $100 \mu \mathrm{M}$ showed only a $17 \pm 8$ and $12 \pm 2 \%$ antiproliferative effect $48 \mathrm{~h}$ after incubation (Fig. 1). 


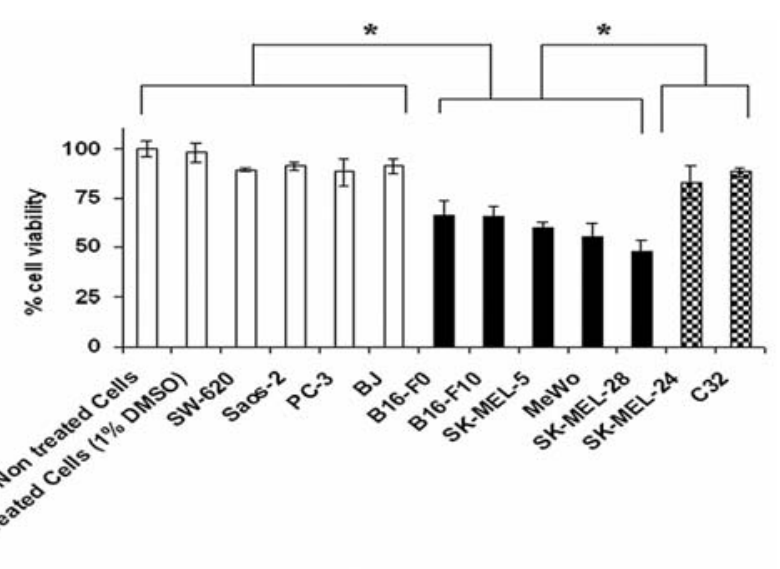

Figure 1. APAP toxicity in melanoma cells and non-melanoma cell lines. APAP $(100 \mu \mathrm{M})$ demonstrated considerable toxicity in melanocytic melanoma cell lines (SK-MEL-28, SK-MEL-5, MeWo, B16-F0 and B16-F10) at $48 \mathrm{~h}$ incubation time in comparison to amelanotic SK-MEL-24 and C32 cells and non-melanoma BJ skin fibroblast, prostate (PC-3), colorectal adenocarcinoma (SW-620), and osteosarcoma (Saos-2) cells. These findings indicate that APAP was selectively toxic towards melanoma cells which express functional tyrosinase but not against amelanotic SK-MEL-24 and C32 melanoma cells which do not express functional tyrosinase and nonmelanoma cell lines.

APAP demonstrated negligible toxicity at $100 \mu \mathrm{M}$ when tested against non-melanoma cell lines such as prostate (PC-3) cells (viability $88 \pm 7 \%$ ), BJ skin fibroblast cells (viability $91 \pm 4 \%$ ), osteosarcoma (Saos-2) cells (viability $91 \pm 2 \%$ ) and non-melanoma colorectal adenocarcinoma (SW-620) cells (viability $89 \pm 1 \%$ ) (Fig. 1). When incubated with APAP $100 \mu \mathrm{M}$ the viability of non-melanoma cells was similar to those of amelanotic melanoma cells. These findings indicate that APAP was significantly and selectively more toxic towards melaocytic melanoma cell lines that express tyrosinase than non-melanoma and amelanotic SK-MEL-24 and C32 melanoma cells, which do not express tyrosinase activity (23).

Intracellular GSH measurement. The effect of APAP on intracellular GSH depletion was also investigated in human melanocytic SK-MEL-28, murine melanocytic B16-F0 and human amelanotic C32 melanoma cells. Our findings indicate that $\operatorname{APAP}(100,250$ and $500 \mu \mathrm{M})$ depleted 12, 22 and $55 \%$ of intracellular GSH at $2 \mathrm{~h}$ incubation with human SK-MEL-28 melanoma cells (Fig. 2A). Similarly, APAP (100, 250 and $500 \mu \mathrm{M}$ ) depleted 9,20 and $56 \%$ of intracellular GSH at $2 \mathrm{~h}$ incubation with murine B16-F0 melanoma cells (Fig. 2B). However, in comparison, at $2 \mathrm{~h}$ incubation with human amelanotic C32 melanoma cells, APAP (100, 250 and $500 \mu \mathrm{M})$ depleted 7, 10 and 13\% of intracellular GSH (Fig. 2C). Our findings indicate that both human SK-MEL-28 and murine B16-F0 melanocytic melanoma cells were more susceptible to APAP toxicity than human amelanotic C32 melanoma cells. Negligible GSH depletion was seen in the absence of APAP.

To ensure that the depletion in the GSH intracellular level was due to the direct APAP induced cell toxicity but not a change in cell viability, the intracellular GSH was not measured beyond $3 \mathrm{~h}$ after the addition of the APAP. This is because a significant drop in cell viability was observed $3 \mathrm{~h}$ after incubation as measured by MTT assay when one million cells were seeded per well in a 24-well plate (data not shown) to enhance the analytical accuracy and sensitivity of the measurement.

Reactive oxygen species formation. Reactive oxygen species (ROS) formation was investigated using the 2',7'-dichlorofluorescein (16) assay when APAP was incubated with human melanocytic SK-MEL-28, murine melanocytic B16-F0 and human amelanotic $\mathrm{C} 32$ melanoma cells. Our results indicate that APAP at concentrations ranging from 50-500 $\mu \mathrm{M}$ at various time points showed a dose- and time-dependent escalation in ROS formation in both human melanocytic SK-MEL-28 melanoma cells (Fig. 2D) and murine melanocytic B16-F0 melanoma cells (Fig. 2E), whereas no significant ROS formation was observed in amelanotic C32 melanoma cells (Fig. 2F), which do not express functional tyrosinase (23).

Drug sensitivity assay in tyrosinase shRNA-transfected cells. APAP $(100 \mu \mathrm{M})$ toxicity in SK-MEL-28 cells was investigated in tyrosinase shRNA-transfected cells. A non-specific shRNA (NS-shRNA) plasmid was used as control. Transfection with the shRNA clone 3 which curtailed tyrosinase expression by $50 \%$ resulted in a significant and reproducible reduction of APAP toxicity. The percentage of cell viability as determined by the MTT assay was $52 \pm 4 \%$ for untransfected cells compared to the $88 \pm 4 \%$ in tyrosinase shRNA-transfected cells (Fig. 3B). No increase in SK-MEL-28 cell viability was observed in wells treated with the tyrosinase non-specific shRNA plasmid (NS-shRNA), thereby suggesting that APAP induced melanoma cell toxicity was primarily due to tyrosinase-mediated activation of APAP.

Enzymatic oxidation of APAP and phenacetin by tyrosinasel $\mathrm{O}_{2}$. APAP showed $87 \%$ depletion of GSH after $2 \mathrm{~h}$ incubation with tyrosinase (Fig. 4A) which translates to $1.7 \mathrm{~mol} \mathrm{GSH}$ per mol of APAP; while phenacetin demonstrated 9\% GSH depletion (Fig. 4A) which translates to $0.18 \mathrm{~mol} \mathrm{GSH}$ per mole of phenacetin after $2 \mathrm{~h}$ incubation with tyrosinase, which suggests that APAP was bioactivated to a quinone by tyrosinase and hence able to react with GSH in contrast to phenacetin. Negligible GSH depletion occurred in the absence of the enzyme (data not shown). The amount of GSH depletion over the indicated incubation times was used to estimate the GSH depletion rate.

The rate of $A A$ and $\mathrm{NADH}$ oxidation by tyrosinase $/ \mathrm{O}_{2}$. The extent of AA and NADH depletion were used to measure the extent of enzymatic oxidation of APAP and phenacetin by tyrosinase $/ \mathrm{O}_{2}$. The rate of AA and NADH oxidation as a result of APAP metabolism by tyrosinase was $0.182 \mu \mathrm{M}$ of AA and $0.101 \mu \mathrm{M}$ of NADH per APAP $(\mu \mathrm{M})$ per tyrosinase $(\mathrm{U} / \mathrm{ml})$ per min, respectively (Fig. 4B). However, the rate of AA and NADH oxidation mediated by tyrosinase in the presence of phenacetin was $0.006 \mu \mathrm{M}$ of AA and $0.05 \mu \mathrm{M}$ of NADH per phenacetin $(\mu \mathrm{M})$ per tyrosinase $(\mathrm{U} / \mathrm{ml})$ per min, respectively (Fig. 4B), which were negligible in comparison to AA and NADH oxidation in presence of APAP and tyrosinase. These 

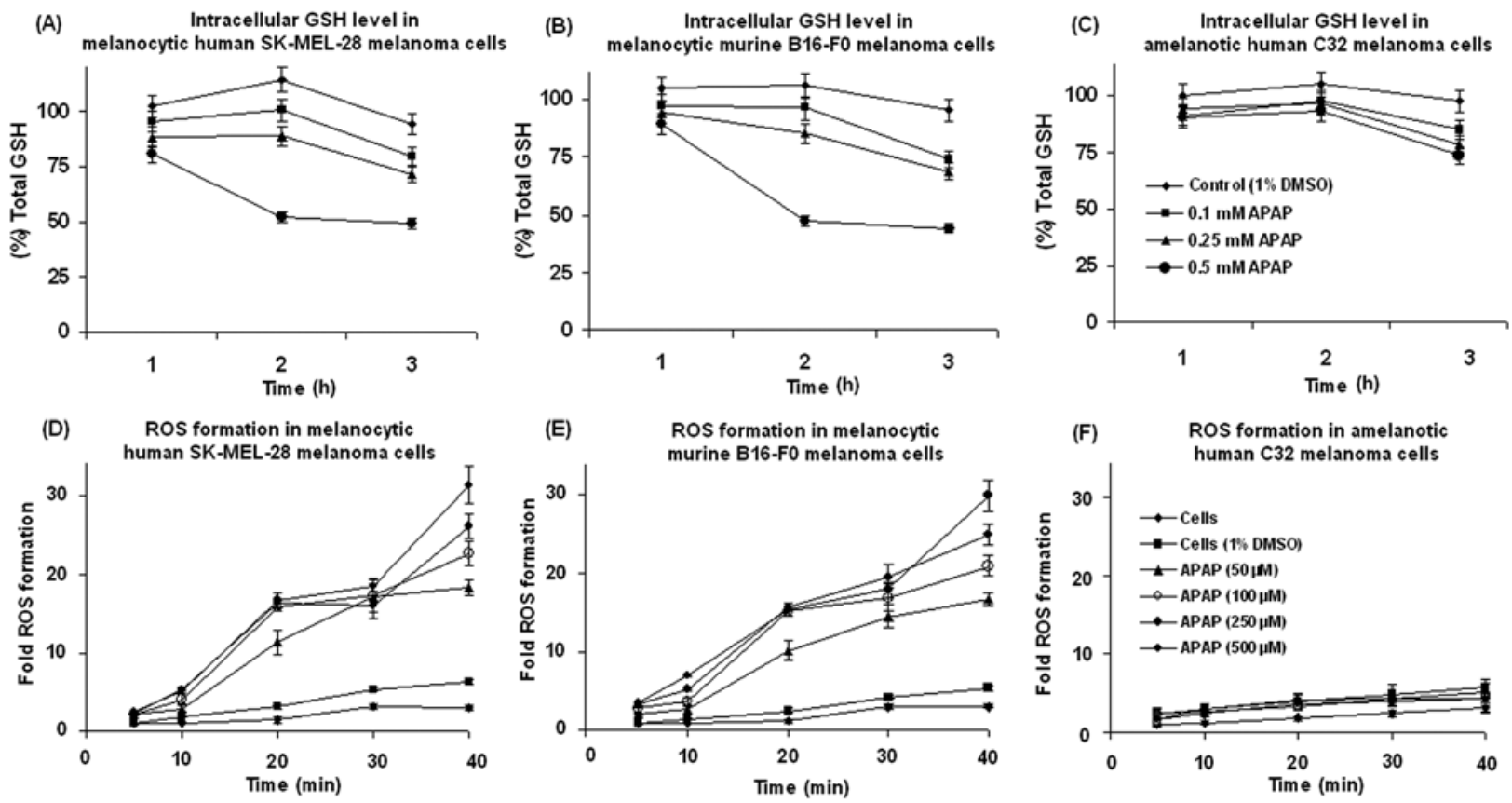

Figure 2. Selective intracellular GSH depletion and ROS formation in human melanocytic SK-MEL-28 and murine melanocytic B16-F0. (A) Intracellular GSH depletion by APAP in human melanocytic SK-MEL-28 melanoma cells. (B) Intracellular GSH depletion by APAP in murine melanocytic B16-F0 melanoma cells and (C) intracellular GSH level in human amelanotic C32 melanoma cells. APAP (100-500 $\mu$ M) showed dose- and time-dependent intracellular GSH depletion in melanocytic human SK-MEL-28 and murine B16-F0 melanoma cells, which express functional tyrosinase, but not in amelanotic C32 melanoma cells, which do not express functional tyrosinase. (D) APAP (50-500 $\mu \mathrm{M})$ led to a time- and dose-dependent escalation in ROS formation in melanocytic human SK-MEL-28 and (E) murine melanocytic B16-F0 melanoma cells. (F) APAP (50-500 $\mu$ M) did not lead to significant ROS formation in amelanotic C32 melanoma cells.

findings indicate that in contrast to APAP, phenacetin cannot be bioactivated by tyrosinase to a quinone and hence it cannot deplete AA and NADH. The addition of GSH significantly diminished the rate of AA and NADH oxidation mediated by metabolic bioactivation of APAP to a quinone in presence of tyrosinase, which could be attributed to a reaction between GSH and APAP quinone as outlined in Fig. 6.

APAP in vivo efficacy study in tumor-bearing mice. The in vivo efficacy of APAP was evaluated at $60-300 \mathrm{mg} / \mathrm{kg} / \mathrm{d}$; in a s.c. B16-F0 melanoma tumor model of C57BL/6 mice. The dosing period varied depending on the tumor growth rate and generally covered the exponential tumor growth period. The results of representative studies of different time points are summarized in Table I. Fig. 5A and B show the dose-dependent efficacy of APAP against B16-F0 murine melanoma when tumor-bearing mice were treated at different doses daily for 13 and 7 days, respectively. When compared to saline treated controls, the animals receiving APAP at 60, 80, 100 and $300 \mathrm{mg} / \mathrm{kg}$ one day post cell inoculation through day 13 demonstrated tumor size growth inhibition by $11 \pm 7,33 \pm 9,36 \pm 20$ and $44 \pm 28 \%$, respectively (Fig. 5A). Similarly, when compared to salinetreated controls, the animals receiving APAP at 60, 80, 100 and $300 \mathrm{mg} / \mathrm{kg}$ day, day 7 post cell inoculation through day 13 demonstrated tumor size growth inhibition by $7 \pm 14$, $30 \pm 17,45 \pm 11$ and $57 \pm 3 \%$, respectively (Fig. 5B). The average tumor size for control mice receiving $120 \mu \mathrm{l}$ saline alone day 1 through day 13 was $2504 \pm 813 \mathrm{mg}$ (range: 1693$4355 \mathrm{mg}$ ), while the average tumor size in control mice receiving $120 \mu \mathrm{l}$ saline alone day 7 through day 13 was $2713 \pm 895 \mathrm{mg}$ (range: 1756-4877 mg), respectively. No statistically significant difference in efficacy was observed when therapy was initiated 1 day or 7 days after melanoma cell inoculation.

In vivo toxicology. In parallel with the in vivo efficacy evaluation, the animal weights were measured on a daily basis. There were no significant difference between animal weights of drug-treated animals (APAP: 60, 80, 100 and $300 \mathrm{mg} / \mathrm{kg}$ ) and those of saline-treated control animals. In addition, plasma samples and liver and kidney tissue from respective treatment groups of melanoma tumor bearing mice were obtained for toxicological analysis.

Assessment of liver toxicity. Analysis of blood samples obtained by heart tap revealed that there were no significant differences in the plasma ALT level of the vehicle-treated control mice and the mice treated with $\operatorname{APAP}(60,80,100$ and $300 \mathrm{mg} / \mathrm{kg}$ ) (Table I).

Estimation of lipid peroxidation in liver and kidney. MDA was used as a measure of lipid peroxidation. No significant increase in MDA concentration was found in the liver and kidney homogenate of the mice treated with varying doses of APAP $(60,80$ and $100 \mathrm{mg} / \mathrm{kg})$ regardless of the day drug therapy was initiated (day 1 or day 7) post melanoma cell inoculation (Table I). Mice receiving APAP (300 mg/kg) demonstrated $81 \pm 10$ and $54 \pm 9 \%$ elevation in lipid peroxidation in the liver and kidney homogenate of C57BL/6 mice, respectively, in comparison to saline treated control animals for the 13-day treatment protocol. APAP $(300 \mathrm{mg} / \mathrm{kg})$ demonstrated $51 \pm 12$ and $44 \pm 7 \%$ elevation in lipid peroxi- 
(A)

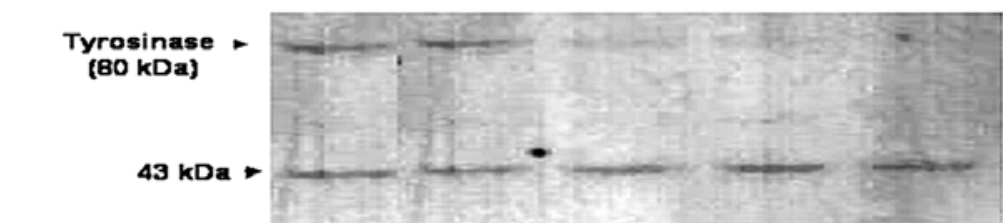

(B)

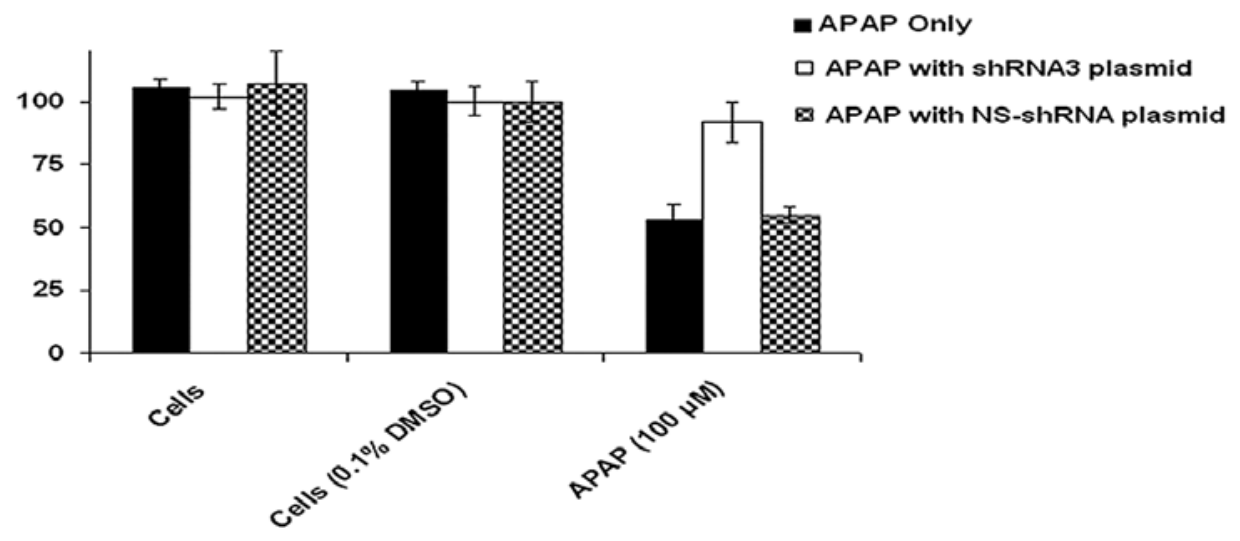

Figure 3. APAP toxicity in the presence and absence of tyrosinase shRNA silencing plasmid. (A) Tyrosinase protein levels were detected by Western blotting with a specific anti-tyrosinase monoclonal antibody. The anti-tyrosinase monoclonal antibody recognizes tyrosinase ( $80 \mathrm{kDa})$ and an unknown band at $43 \mathrm{kDa}$ (as described by antibody manufacturer's manual). Transfection with shRNA3 clone curtailed tyrosinase expression. (B) APAP (100 $\mu \mathrm{M})$ did not cause significant toxicity in SK-MEL-28 cells silenced with shRNA plasmid directed against tyrosinase.

(A)

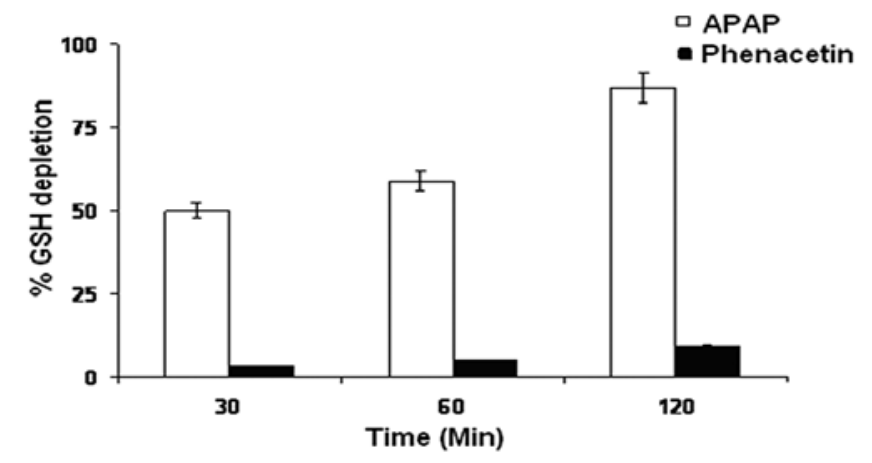

(B)

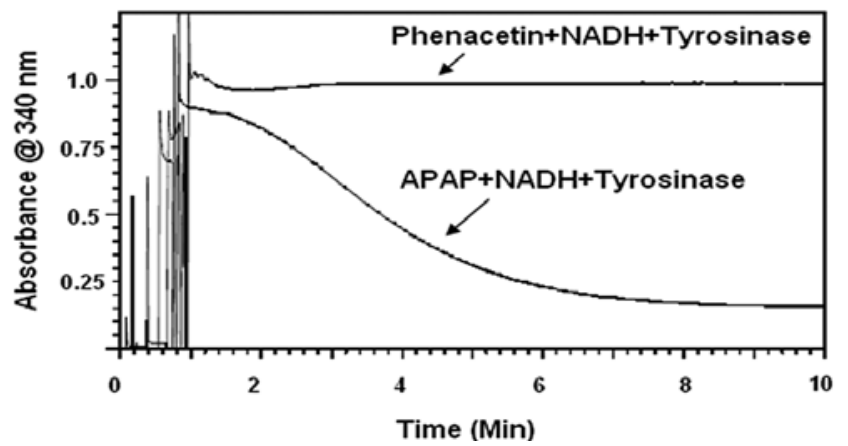

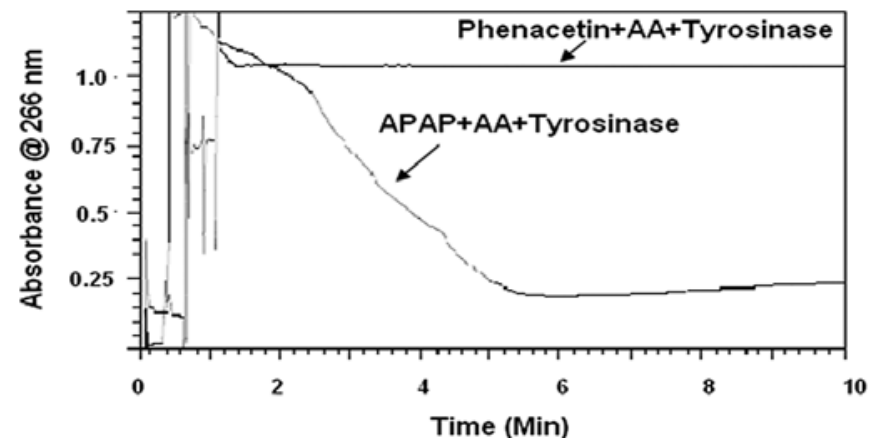

Figure 4. Tyrosinase mediated oxidation of APAP and phenacetin. (A) \% GSH depletion mediated by the enzymatic oxidation of APAP or phenacetin by tyrosinase. On a molar basis 1.7 and $0.18 \mathrm{~mol}$ GSH was depleted when APAP and phenacetin were enzymatically oxidized by APAP and phenacetin, respectively. (B) Kinetic scan for the enzymatic oxidation of APAP and phenacetin at $\mathrm{pH} 7.4$ by tyrosinase $/ \mathrm{O}_{2}$. AA and NADH oxidations were monitored at 266 and $340 \mathrm{~nm}$, respectively. The results suggest that APAP metabolism by tyrosinase forms an o-quinone which could react with AA and NADH.

dation in the liver and kidney homogenate, respectively of C57BL/6 mice when drug treatment was initiated on day 7 post melanoma cell inoculation, in comparison to saline-treated control animals (Table I).
Estimation of free thiols in liver and kidney. No significant depletion in free thiol content was found in the liver and kidney homogenate of B16-F0 tumor-bearing mice treated with varying doses of APAP $(60,80$ and $100 \mathrm{mg} / \mathrm{kg})$ 

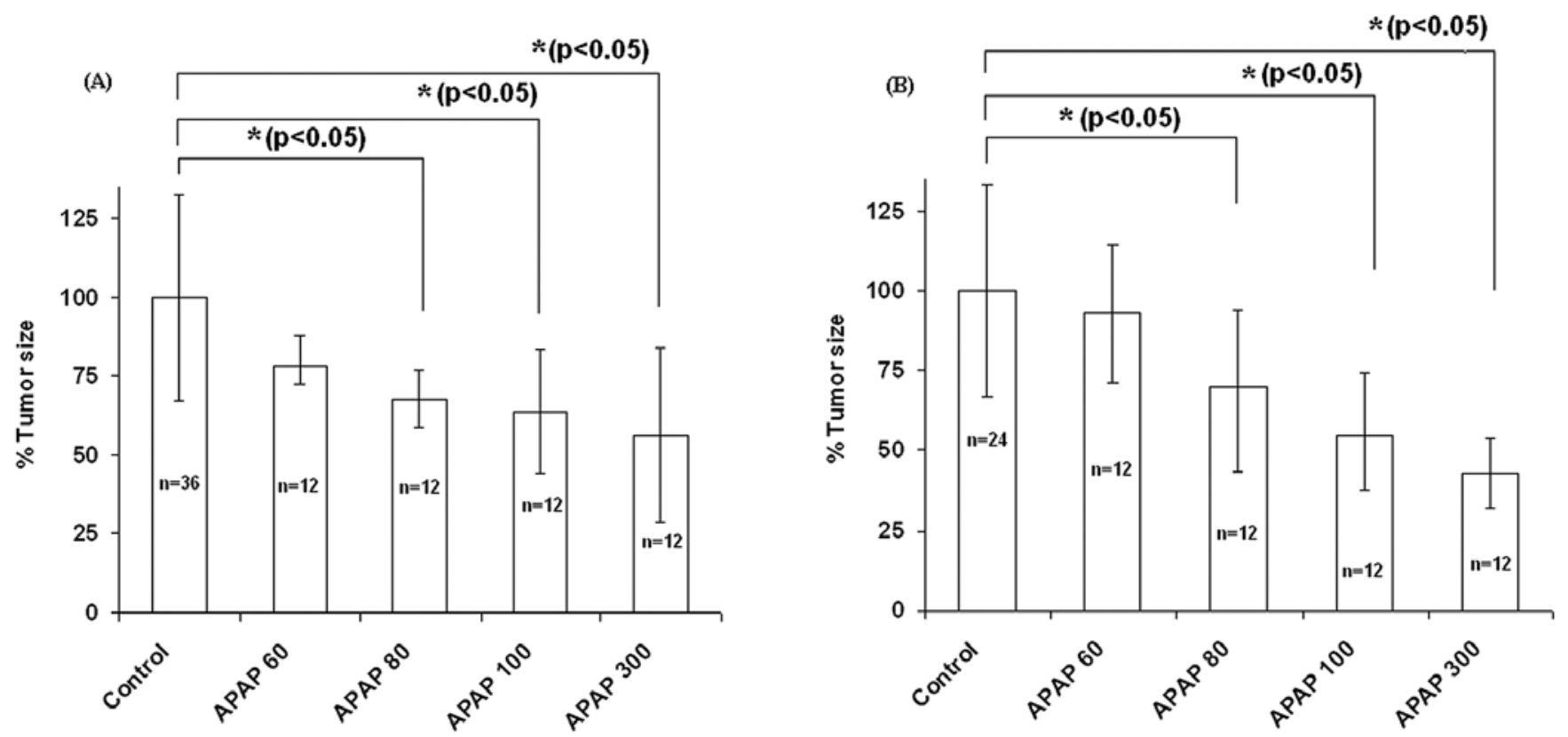

Figure 5. APAP in vivo efficacy in melanoma tumor-bearing mice. (A) When compared to controls, the animals $(\mathrm{n} \geq 12)$ receiving APAP at $60,80,100$ and $300 \mathrm{mg} / \mathrm{kg}$ (in saline, i.p.) day 1 through day 13 post melanoma cell inoculation demonstrated tumor size growth inhibition by $11 \pm 7,33 \pm 9,36 \pm 20$ and $44 \pm 28 \%$, respectively. (B) Similarly, when compared to controls, the animals $(\mathrm{n} \geq 12)$ receiving APAP at $60,80,100$ and $300 \mathrm{mg} / \mathrm{kg}$ (in saline, i.p.) day 7 through day 13 demonstrated tumor size growth inhibition by $7 \pm 38,30 \pm 38,45 \pm 34$ and $57 \pm 18 \%$, respectively. Control mice received saline alone.

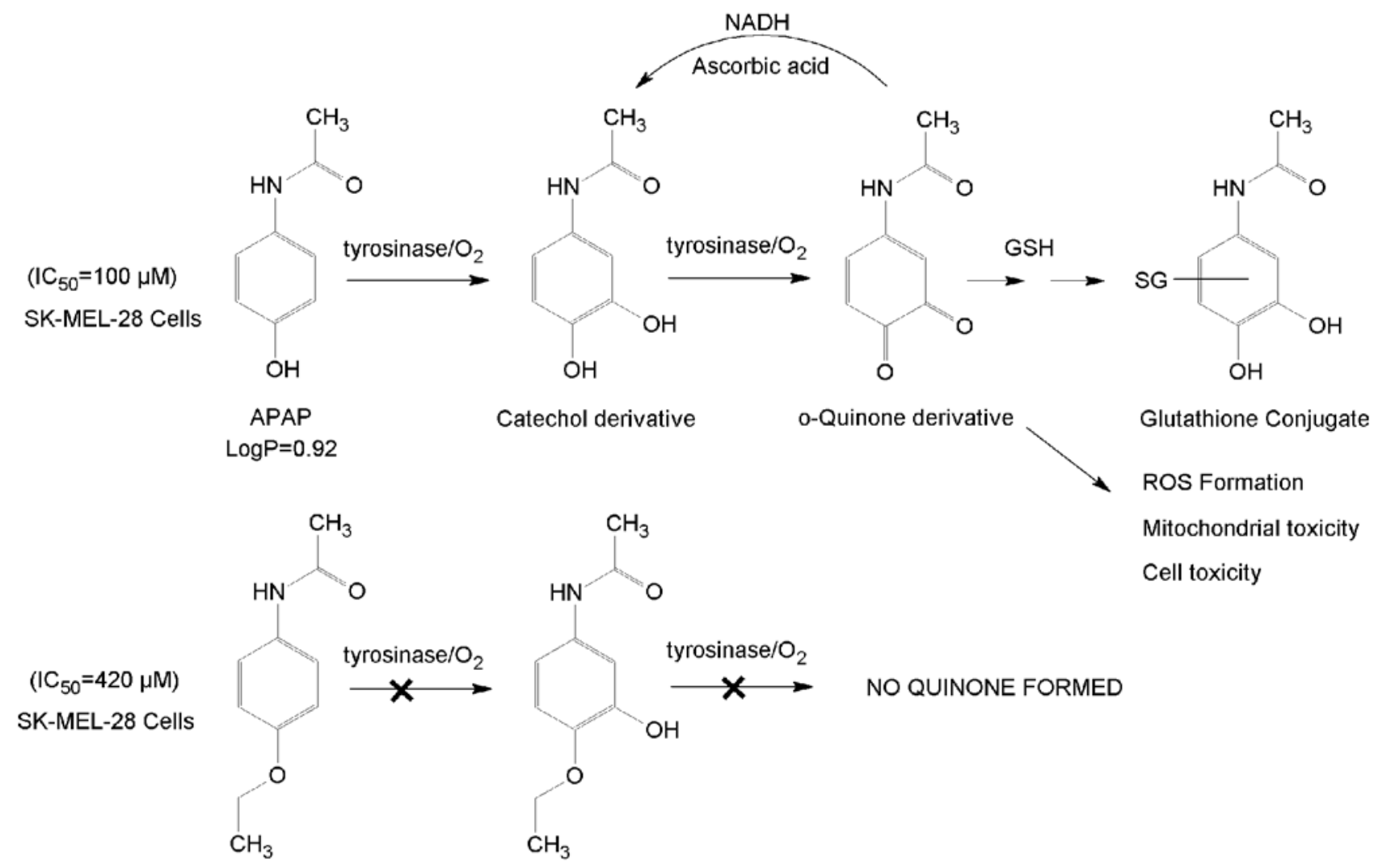

Phenacetin

$\log \mathrm{P}=1.63$

Figure 6. Proposed biochemical mechanism for APAP toxicity in SK-MEL-28 melanoma cells. Phenacetin does not contain a phenol group and hence cannot be activated by tyrosinase to a catechol and then to a toxic quinone, whereas APAP can form a quinone as a result of APAP bioactivation by tyrosinase. Our findings indicate that the phenolic entity is an essential functional group in the APAP structure for its selective toxicity towards melanoma cell lines. 
Table I. Summary of APAP in vivo toxicological and efficacy in melanoma tumor-bearing mice. ${ }^{\mathrm{a}}$

Treatment (i.p. injection)

$60 \mathrm{mg} / \mathrm{kg} /$ day $\quad 80 \mathrm{mg} / \mathrm{kg} /$ day $\quad 100 \mathrm{mg} / \mathrm{kg} /$ day $\quad 300 \mathrm{mg} / \mathrm{kg} /$ day

\section{Day 1-13 APAP therapy}

Tumor regression (\%)

Plasma ALT levels (IU/l) ${ }^{\mathrm{b}}$

Depletion in free thiols (\%)

Liver

Kidney

Elevation in lipid peroxidation (\%) as measured by TBARS

Liver

Kidney

\section{Day 7-13 APAP therapy}

Tumor regression (\%)

Plasma ALT levels (IU/1) ${ }^{\mathrm{b}}$

Depletion in free thiols (\%)

Liver

Kidney

Elevation in lipid peroxidation (\%) as measured by TBARS

$$
\text { Liver }
$$

Kidney

\begin{tabular}{cccc}
$11 \pm 7 \%$ & $33 \pm 9 \%$ & $36 \pm 20 \%$ & $44 \pm 28 \%$ \\
$94 \pm 8$ & $103 \pm 10$ & $58 \pm 15$ & $70 \pm 26$ \\
& & & \\
$9 \pm 5 \%$ & $20 \pm 3 \%$ & $8 \pm 4 \%$ & $15 \pm 9 \%$ \\
$14 \pm 7 \%$ & $24 \pm 4 \%$ & $11 \pm 8 \%$ & $17 \pm 13 \%$ \\
& & & \\
$3 \pm 7 \%$ & $27 \pm 5 \%$ & $26 \pm 8 \%$ & $81 \pm 10 \%$ \\
$1 \pm 8 \%$ & $27 \pm 10 \%$ & $17 \pm 6 \%$ & $54 \pm 9 \%$ \\
& & & \\
& & & \\
$7 \pm 14 \%$ & $30 \pm 17 \%$ & $45 \pm 11 \%$ & $57 \pm 3 \%$ \\
$76 \pm 7$ & $80 \pm 7$ & $80 \pm 21$ & $86 \pm 17$ \\
$5 \pm 6 \%$ & $6 \pm 10 \%$ & $13 \pm 5 \%$ & $26 \pm 6 \%$ \\
$4 \pm 6 \%$ & $7 \pm 6 \%$ & $13 \pm 10 \%$ & $23 \pm 11 \%$ \\
$1 \pm 5 \%$ & $1 \pm 7 \%$ & $6 \pm 11 \%$ & $51 \pm 12 \%$ \\
$5 \pm 6 \%$ & $5 \pm 5 \%$ & $1 \pm 8 \%$ & $44 \pm 7 \%$ \\
\hline
\end{tabular}

${ }^{a}$ Male C57BL/6 mice (6-8 weeks, $\mathrm{n} \geq 12$ ) were inoculated s.c. (day 0) on the right flank with $1 \times 10^{6} \mathrm{~B} 16-\mathrm{F} 0$ melanoma cells in $100 \mu 1 \mathrm{PBS}$. APAP $(60,80,100$ and $300 \mathrm{mg} / \mathrm{kg} /$ day in $120 \mu \mathrm{l}$ saline) was administered i.p. on day 1 and day 7 post melanoma cell inoculation and continued daily for 13 and 7 days, respectively. The non-treated control animals received $120 \mu 1$ saline only. All animals were weighed daily and sacrificed $2 \mathrm{~h}$ post drug injection on day 13 after inoculation. No significant differences in body weight were observed in control mice that received saline and APAP in treatment groups. Plasma ALT levels, lipid peroxidation and free thiol content of the liver and kidney were measured as biomarkers of APAP induced in vivo toxicity. Negligible in vivo toxicity was observed when APAP was administered at 60,80 and $100 \mathrm{mg} / \mathrm{kg} /$ day i.p. while APAP at $300 \mathrm{mg} / \mathrm{kg}$ caused a 50-80\% elevation in lipid peroxidation and $20 \%$ depletion in free thiol content in the liver and kidney of melanoma tumor bearing mice, respectively, when compared to controls. ${ }^{\text {b}}$ The plasma ALT levels (IU/l) as measured in

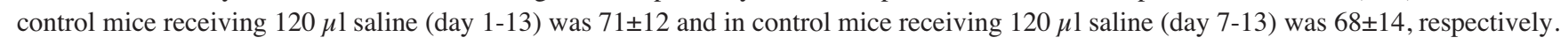

(Table I). Mice receiving APAP $(300 \mathrm{mg} / \mathrm{kg})$ demonstrated $15 \pm 9$ and $17 \pm 13 \%$ depletion in free thiol content in the liver and kidney homogenate of C57BL/6 mice, respectively when drug treatment was initiated on day 1 post melanoma cell inoculation, in comparison to saline-treated control animals. APAP (300 mg/kg) demonstrated $26 \pm 6$ and $23 \pm 11 \%$ depletion in free thiol content in the liver and kidney homogenate of C57BL/6 mice, respectively, when drug treatment was initiated on day 7 post melanoma cell inoculation, in comparison to saline control animals (Table I).

Partition coefficient. The Log P-value for APAP and phenacetin was estimated to be 0.92 and 1.63 using the program available on www.acdlabs.com. Hence, the antilog partition coefficient values of APAP and phenacetin are 8.3 and 42.7, respectively; which indicates that phenacetin is $\sim 5$-fold more lipid soluble than APAP.

\section{Discussion}

Treatment of metastatic melanoma by chemotherapeutic drugs is offset by problems of lack of specificity and toxicity (25).
A number of enzymes are involved in melanin synthesis; however only tyrosinase is unique to the melanocytes (7). The presence of tyrosinase in human melanomas has led to a rational prodrug targeted approach towards this disease $(7,8)$. Tyrosinase has previously been used as a molecular target in melanoma directed enzyme prodrug therapy $(7,9,11)$. It has also been shown that tyrosinase expression in transfected non-melanotic cells can be used to activate prodrugs for nonmelanocytic cell treatment (26).

In our studies, we used tyrosinase as a molecular target to develop anti-melanoma drugs that could be bioactivated intracellularly to selectively target malignant cells, while sparing normal tissues devoid of the enzyme from unwanted drug toxicity. Previously, we showed that APAP was selectively bioactivated by melanoma tyrosinase to active quinone metabolites which were cytotoxic to melanoma (27). In the current study, in order to further substantiate the tyrosinase-mediated toxicity hypothesis, we investigated drug induced toxicity using tyrosinase shRNA plasmid constructs targeted towards tyrosinase expression in human melanocytic SK-MEL-28 melanoma cells. Short hairpin RNAs (shRNAs) are characterized by base paired stems and a loop region 
(28). They are processed by a dicer into siRNAs that are 21to 23-base pair duplexes typically containing two-base 3'overhangs. These systems in association with a promoter achieve good knockdown for the desired target (28). Our results indicate that APAP $(100 \mu \mathrm{M})$ did not mediate cell toxicity when tyrosinase was silenced by shRNA plasmid, thus providing further evidence that APAP toxicity was mediated by tyrosinase in human melanoma cells.

We also investigated the in vitro anti-proliferative effects of APAP as an anti-melanoma agent in melanoma cell lines such as human melanocytic SK-MEL-28 and murine melanocytic B16-F0 melanoma cells that express functional tyrosinase in comparison to amelanotic human SK-MEL-24 and C32 melanoma cells and other non-melanoma cell lines that do not express functional tyrosinase (23). Our results suggest that APAP is selectively toxic towards melanoma cells which suggests that tyrosinase mediated formation of reactive species is responsible for this selective toxicity.

Furthermore, in this study, we showed that APAP led to significant escalation in ROS formation when it was incubated with human melanocytic SK-MEL-28 and murine melanocytic B16-F0 melanoma cells which express functional tyrosinase whereas no significant ROS formation was observed in human amelanotic C32 melanoma cells, which do not express functional tyrosinase (23). In addition, APAP caused significant depletion in intracellular GSH concentration in both human melanocytic SK-MEL-28 and murine melanocytic B16-F0 melanoma cells while it caused a marginal decline in intracellular GSH in human amelanotic $\mathrm{C} 32$ cells suggesting that melanocytic SK-MEL-28 and B16-F0 melanoma cells which express functional tyrosinase were more susceptible to APAP than amelanotic C32 melanoma cells (Fig. 2). Previously, we also showed that APAP at $100 \mu \mathrm{M}$ was selectively toxic towards melanoma cells while it led to negligible toxicity towards primary normal melanocytes (9). One explanation for this observation could be that tyrosinase is over expressed in melanoma cells as compared to normal melanocytes. Indeed, Chen et al have shown in a study of tyrosinase prepared from normal skin and metastatic melanoma from the same patient, that 46 to 95 units per mg were found in the skin and 17,000 to 19,500 units per $\mathrm{mg}$ in the melanoma (29).

In addition, phenacetin [ $N$-(4-Ethoxyphenyl)acetamide] was investigated for its metabolism and bioactivation by tyrosinase enzyme and its toxicity in melanoma cell culture experiments. Phenacetin (Fig. 6), which lacks the APAP phenol group, is a structural analog of APAP and was used here to investigate the role of the phenolic functional group in APAP toxicity against melanoma cell lines. The $\mathrm{IC}_{50}$ for phenacetin was found to be $420 \mu \mathrm{M}$, thus demonstrating a 4.2-fold decrease in its toxicity as compared to APAP $(100 \mu \mathrm{M})$. Phenacetin is 5-fold more lipid soluble than APAP. As a general rule, the more lipid soluble a drug is the more efficacious or toxic a drug should be. Hence by taking lipid solubility into account, phenacetin, contrary to what was expected, showed a 21-fold (5-fold increase lipid solubility $\mathrm{x}$ 4.2-fold APAP $\mathrm{IC}_{50}$ ) reduction in its toxicity. This indicates that phenol entity of APAP (Fig. 6) is an important functional group and it plays a major role in APAP induced toxicity in melanoma cells, whereas masking the APAP phenol group with an ethyl group in phenacetin prevented the latter from being as toxic as APAP towards melanoma cells. Results from tyrosinase-mediated GSH depletion assay and UV-Vis spectral studies revealed that phenacetin is also a poor substrate for tyrosinase and did not cause GSH, ascorbic acid (AA) and NADH depletion. This can be explained by the fact that phenacetin does not contain a phenol group and hence cannot be activated to a catechol and further to a toxic quinone by tyrosinase and therefore it cannot react with and deplete GSH or oxidize AA and NADH. In contrast, the quinone formed as a result of APAP bioactivation by tyrosinase could react with GSH, NADH and AA and hence deplete these agents in reaction media (Figs. 4 and 6).

Because the anti-proliferative effect of APAP, its effect on ROS formation and intracellular GSH depletion were similar in human melanocytic SK-MEL-28 and murine melanocytic B16-F0 melanoma cells, we decided to investigate the in vivo efficacy of APAP in a skin tumor model of murine B16-F0 melanoma tumor-bearing C57BL/6 mice. Our in vivo efficacy study in B16-F0 melanoma-bearing C57BL/6 mice showed that administration of APAP (80, 100 and 300 $\mathrm{mg} / \mathrm{kg} /$ day) caused significant tumor growth inhibition as measured in melanoma skin tumor model of C57BL/6 mice. Toxicological data as measured by plasma ALT, free thiol content, and lipid peroxidation in the liver and kidney as biomarkers of drug induced toxicity indicates no significant toxicity when APAP was administered at 60, 80 and 100 $\mathrm{mg} / \mathrm{kg} /$ day while some toxicity was observed when APAP was administered at $300 \mathrm{mg} / \mathrm{kg} /$ day in treatment protocols, thus leading us to suggest that regular dose acetaminophen (APAP) might be effective in causing melanoma tumor regression without any significant associated toxicity. Because APAP showed similar toxicity towards human and murine melanoma cell lines (Fig. 1), we therefore anticipate a similar response against melanoma in humans.

APAP has been used effectively and safely by a large number of patients for its analgesic and anti-pyretic effects (30) and has been considered one of the safest drugs. Acute toxicity is rarely seen in adults ingesting $<10 \mathrm{~g}$ and fatalities are rare with ingestions $<15 \mathrm{~g}$ (31). APAP is metabolized in the liver primarily to its glucuronide and sulfate conjugates. These polar metabolites are relatively non-toxic and are eliminated by the kidneys along with trace amounts of unmetabolized drug (31). A minor metabolic pathway involves oxidation by cytochrome P450 mixed-function oxidase, forming a reactive metabolite which can either be converted to other metabolites (such as cysteine and mercapturic acid) and excreted, or can be bound to hepatic macromolecules causing hepatic necrosis (30). The toxicity of APAP in man and other animals is dependent on the degree of hepatic GSH depletion which occurs. This rate of depletion and the corresponding production of the GSH conjugate are dependent on the concentrations of intracellular GSH and APAP (31). Savides and Oehme have shown that the extent of hepatic necrosis correlated well with the degree of hepatic GSH depletion (31). The study also demonstrated differences in APAP metabolism in mice and man. Mice metabolize APAP much more effectively and hence can tolerate higher doses of the drug than in man (31). 
Earlier, Wolchok et al conducted a phase I trial of high dose APAP (10 and $15 \mathrm{~g} / \mathrm{m}^{2}$ ) and carmustine in patients with metastatic melanoma (32). Patients were administered eight cycles of high dose APAP $\left(20 \mathrm{~g} / \mathrm{m}^{2}\right)$ followed by administration of $\mathrm{N}$-acetyl cysteine (NAC) 6-8 h post APAP ingestion after each cycle, repeated every three weeks with and without carmustine every other three week cycle. Marked reduction in size of liver metastases and lung nodules was noted in some patients while others showed partial response. The trial was terminated after eight cycles of APAP and four cycles of carmustine therapy after the patients elected to suspend therapy (32). The authors indicated that the observed efficacy may be due to APAP administration, but the use of such high dose of APAP that could potentially cause acute clinical toxicity necessitated NAC administration to initiate rescue. Although we agree with the use of NAC to rescue the patients from developing severe liver failure, we believe that NAC administration significantly diminished the effect of APAP and carmustine combo therapy in their study. In addition, Wolchok et al (32) did not investigate the role of tyrosinase in APAP bioactivation and the bio-chemical mechanism of APAP induced toxicity in melanoma cell lines.

Our findings indicate that the $\mathrm{IC}_{50}(48 \mathrm{~h})$ for APAP in SK-MEL-28 human melanoma cells was $100 \mu \mathrm{M}$ (9) which is within the APAP therapeutic concentration with an average peak concentration $132 \mu \mathrm{M}$ (range: 66-200 $\mu \mathrm{M}$ ) as an analgesic agent (30) and that a $100 \mu \mathrm{M}$ concentration for APAP does not require NAC administration and is achievable with $4 \mathrm{~g}$ daily administration ( $1 \mathrm{~g}$ every $6 \mathrm{~h}$ ).

In summary, we showed that tyrosinase plays a major role in APAP bioactivation and its selective toxicity towards melanocytic melanoma cells and that administration of APAP caused significant tumor growth inhibition in B16-F0 skin tumor model of melanoma in C57BL/6 mice. These findings suggest that APAP should be further investigated as an antimelanoma agent in future.

\section{Acknowledgements}

This study was supported partly by a grant from NIH (1R15CA122044-01A1) and the TTUHSC School of Pharmacy.

\section{References}

1. Lens MB and Dawes M: Global perspectives of contemporary epidemiological trends of cutaneous malignant melanoma. Br J Dermatol 150: 179-185, 2004.

2. Garbe C, McLeod GR and Buettner PG: Time trends of cutaneous melanoma in Queensland, Australia and Central Europe. Cancer 89: 1269-1278, 2000.

3. Diepgen TL and Mahler V: The epidemiology of skin cancer. $\mathrm{Br}$ J Dermatol 146 (Suppl 61): 1-6, 2002.

4. Naish S, Cooksey CJ and Riley PA: Initial mushroom tyrosinase-catalysed oxidation product of 4-hydroxyanisole is 4-methoxy-ortho-benzoquinone. Pigment Cell Res 1: 379-381, 1988.

5. Naish S, Holden JL, Cooksey CJ and Riley PA: Major primary cytotoxic product of 4-hydroxyanisole oxidation by mushroom tyrosinase is 4-methoxy ortho benzoquinone. Pigment Cell Res 1: 382-385, 1988

6. Moridani MY, Cheon SS, Khan S and O'Brien PJ: Metabolic activation of 4-hydroxyanisole by isolated rat hepatocytes. Drug Metab Dispos 30: 1063-1069, 2002.
7. Riley PA, Cooksey CJ, Johnson CI, Land EJ, Latter AM and Ramsden CA: Melanogenesis-targeted anti-melanoma pro-drug development: Effect of side-chain variations on the cytotoxicity of tyrosinase-generated ortho-quinones in a model screening system. Eur J Cancer 33: 135-143, 1997.

8. Riley PA: Hydroxyanisole depigmentation: In-vitro studies. J Pathol 97: 193-206, 1969.

9. Vad NM, Yount G, Moore D, Weidanz J and Moridani MY: Biochemical mechanism of acetaminophen (APAP) induced toxicity in melanoma cell lines. J Pharm Sci 98: 1409-1425, 2009.

10. Moridani MY, Moore M, Bartsch RA, Yang Y and HeibatiSadati S: Structural toxicity relationship of 4-alkoxyphenols' cytotoxicity towards murine B16-F0 melanoma cell line. J Pharm Pharm Sci 8: 348-360, 2005.

11. Vad NM, Yount G and Moridani MY: Biochemical mechanism of acetylsalicylic acid (aspirin $\left.{ }^{\circledR}\right)$ selective toxicity towards melanoma cell lines. Melanoma Res 18: 386-399, 2008.

12. Wu X, Zeng H, Zhang X, et al: Phosphatase of regenerating liver-3 promotes motility and metastasis of mouse melanoma cells. Am J Pathol 164: 2039-2054, 2004.

13. Moridani MY, Cheon SS, Khan S and O'Brien PJ: Metabolic activation of 3-hydroxyanisole by isolated rat hepatocytes. Chem Biol Interact 142: 317-333, 2003.

14. Vad NM, Shaik IH, Mehvar R and Moridani MY: Metabolic bioactivation and toxicity of ethyl 4-hydroxy benzoate in human SK-MEL-28 melanoma cells. J Pharm Sci 97: 1934-1945, 2008.

15. Shaik IH and Mehvar R: Rapid determination of reduced and oxidized glutathione levels using a new thiol-masking reagent and the enzymatic recycling method: Application to the rat liver and bile samples. Anal Bioanal Chem 385: 105-113, 2006.

16. Siraki AG, Chan TS and O'Brien PJ: Application of quantitative structure-toxicity relationships for the comparison of the cytotoxicity of $14 \mathrm{p}$-benzoquinone congeners in primary cultured rat hepatocytes versus PC12 cells. Toxicol Sci 81: 148-159, 2004.

17. Johansen IE: Intron insertion facilitates amplification of cloned virus cDNA in Escherichia coli while biological activity is reestablished after transcription in vivo. Proc Natl Acad Sci USA 93: 12400-12405, 1996.

18. Gergel' D and Cederbaum AI: Interaction of nitric oxide with 2-thio-5-nitrobenzoic acid: Implications for the determination of free sulfhydryl groups by ellman's reagent. Arch Biochem Biophys 347: 282-288, 1997.

19. Ellman GL: Tissue sulfhydryl groups. Arch Biochem Biophys 82: 70-77, 1959.

20. Wills ED: Mechanisms of lipid peroxide formation in animal tissues. Biochem J 99: 667-676, 1966.

21. Kaur G, Tirkey N, Bharrhan S, Chanana V, Rishi P and Chopra K: Inhibition of oxidative stress and cytokine activity by curcumin in amelioration of endotoxin-induced experimental hepatoxicity in rodents. Clin Exp Immunol 145: 313-321, 2006.

22. Sedlak J and Lindsay RH: Estimation of total, protein-bound, and nonprotein sulfhydryl groups in tissue with Ellman's reagent. Anal Biochem 25: 192-205, 1968.

23. Kawai S, Yoshinari M, Matsumoto J, Kirinoki M, Aikawa M, Minami M and Matsuda H: Plasmodium coatneyi-infected erythrocytes bind to $\mathrm{C} 32$ amelanotic melanoma cells under static and flow conditions. J Vet Med Sci 65: 375-380, 2003.

24. Hirosaki K, Yamashita T, Wada I, Jin HY and Jimbow K: Tyrosinase and tyrosinase-related protein 1 require Rab7 for their intracellular transport. J Invest Dermatol 119: 475-480, 2002.

25. Naish-Byfield S, Cooksey CJ, Latter AM, Johnson CI and Riley PA: In vitro assessment of the structure-activity relationship of tyrosinase-dependent cytotoxicity of a series of substituted phenols. Melanoma Res 1: 273-287, 1991.

26. Simonova M, Wall A, Weissleder R and Bogdanov A Jr: Tyrosinase mutants are capable of prodrug activation in transfected nonmelanotic cells. Cancer Res 60: 6656-6662, 2000.

27. Picardo M, Passi S, Nazzaro-Porro M, Breathnach AS, Zompetta C, Faggioni A and Riley P: Mechanism of antitumoral activity of catechols in culture. Biochem Pharmacol 36: 417-425, 1987.

28. Rossi JJ: Expression strategies for short hairpin RNA interference triggers. Hum Gene Ther 19: 313-317, 2008. 
29. Chen YM and Chavin W: Tyrosinase activity in highly pigmented human melanoma and in negro skin. Proc Soc Exp Biol Med 145: 695-698, 1974.

30. Roberts LJ II and Morrow JD: Analgesic-antipyretic and antiinflammatory agents and drugs employed in the treatment of gout. In: The Pharmacological Basis of Therapeutics Hardman JG, Limbird LE and Gilman AG (eds). McGraw-Hill, New York, pp687-692, 2001.
31. Savides MC and Oehme FW: Acetaminophen and its toxicity. J Appl Toxicol 3: 96-111, 1983.

32. Wolchok JD, Williams L, Pinto JT, et al: Phase I trial of high dose paracetamol and carmustine in patients with metastatic melanoma. Melanoma Res 13: 189-196, 2003. 